Corresponding author: Hong.Li@emory.edu

(C) 2020 Gonzalez Garcia et al. This article is distributed under the terms of the Creative Commons Attribution License, which permits unrestricted reuse and redistribution provided that the original author and source are credited.

Ontology terms: delayed gross motor development; downturned corners of mouth; growth hormone deficiency; long upper eyelashes; lumbosacral hirsutism; microcephaly; moderate expressive language delay; synophrys

Published by Cold Spring Harbor Laboratory Press

doi:10.1101/mcs.a005322

\section{A novel mosaic variant on SMC1A reported in buccal mucosa cells, albeit not in blood, of a patient with Cornelia de Lange-like presentation}

\author{
Aixa Gonzalez Garcia, ${ }^{1}$ Julia Malone, ${ }^{1}$ and Hong $\mathrm{Li}^{1,2}$ \\ ${ }^{1}$ Department of Human Genetics, ${ }^{2}$ Department of Pediatrics, Emory University School of Medicine, Atlanta, \\ Georgia 30322, USA
}

\begin{abstract}
Mosaicism in Cornelia de Lange syndrome (CdLS) has been reported in clinically diagnosed CdLS patients with negative molecular testing using blood as the specimen, particularly in the NIPBL gene. Here we report a novel mosaic variant in SMC1A identified in the buccal swab DNA of a patient with a mild CdLS phenotype. Our patient presented with global developmental delay, dysmorphic features, microcephaly, and short stature, with no limb defect. Face2Gene, a digital tool that analyzes facial morphology, demonstrated a 97\% match between our patient and the CdLS gestalt. An initial next-generation sequencing (NGS)-based CdLS panel test, including NIPBL, HDAC8, RAD21, SMC1A, and SMC3, completed using DNA isolated from leukocytes, was negative, and subsequent trio exome sequencing was nondiagnostic. The exome identified biallelic variants of uncertain significance in a candidate gene, NSMCE2. In the pursuit of a molecular diagnosis, a second NGS-based CdLS panel test was ordered on a buccal swab specimen and a novel variant, c.793_795delGAG (p.Glu265del) in SMC1A, was detected at 60\% mosaicism. Retrospective analysis of the former panel and exome data revealed the SMC1A variant at $4 \%$ and $2 \%$, respectively, both far below standard reporting thresholds. Given that mosaicism has been frequently reported in CdLS, we suggest selecting a different tissue for testing in clinically suspected CdLS cases, even after negative molecular results via blood specimen.
\end{abstract}

[Supplemental material is available for this article.]

\section{CASE PRESENTATION}

Here we present a 6-yr-old male with global developmental delays, microcephaly, short stature improved by growth hormone, small penis for age, plus hyperlipidemia, and dysmorphic features reminiscent of Cornelia de Lange syndrome (CdLS).

His gestation was complicated by exposure to buprenorphine and pregabalin for an initial 9 wk, alcohol for $10 \mathrm{wk}$, and tobacco throughout. Normal in utero growth was reported. Patient was born via vaginal delivery at 37 wk gestation to a 22-yr-old primigravida, with a birth weight of 6 pounds. His neonatal course was complicated by meconium aspiration associated with respiratory distress and feeding difficulty due to ankyloglossia. His early developmental milestones were delayed. He sat at $9 \mathrm{mo}$, pulled to stand at $18 \mathrm{mo}$, and began walking at around 24 mo. Developmental Assessment of Young Children-2 (DAYC-2) at age 2 indicated significant developmental delays in all domains: gross motor skills (DAYC2 score 79), fine motor skills (69), receptive and expressive language (64 and 54), social 
COLD SPRING HARBOR Molecular Case Studies
A novel mosaic variant on SMC1A emotional skills (71), and cognition and adaptive skills (70 and 70). He had few words and was not toilet trained by the time of his initial genetics evaluation at $3 \mathrm{yr}$ and 8 mo. Patient had normal head tomography and single-nucleotide polymorphism (SNP) microarray. At the initial genetic evaluation at $3 \mathrm{yr}$ and $8 \mathrm{mo}$ old, his height was $89.10 \mathrm{~cm}(0.39 \%$ ile and -2.66 SDS), weight was $14.10 \mathrm{~kg}$ (20\%ile, -0.84 SDS), and head circumference was $46.1 \mathrm{~cm}$, below the third percentile. His features were reminiscent of the Cornelia de Lange phenotype (see Table 1). Using Face2Gene, a facial digital analysis tool, his gestalt score was a strong match for the CdLS (Fig. 1). Thus, a CdLS next-generation sequencing (NGS)-based gene panel (sequencing and copy-number variant [CNV] analysis), including NIPBL, HDAC8, RAD21, SMC1A, and SMC3, was ordered on a blood specimen, and the result was negative, with no variants of interest reported. In the interim, the patient was diagnosed with growth hormone deficiency. His initial growth velocity was $5.8 \mathrm{~cm} / \mathrm{year}$ (10th percentile), but after initiating growth hormone therapy, velocity improved to $8.9 \mathrm{~cm} /$ year (90th percentile). The response to growth hormone has not been studied systematically on CdLS patients; however, it is consistent with the experience reported by de Graaf et al. (2017). When the patient returned to the clinic at the age of $5 \mathrm{yr}$ and $1 \mathrm{mo}$, his height was $100.2 \mathrm{~cm}$, improved to the third percentile (-2.01 SDS). However, microcephaly persisted and his head circumference was $47.5 \mathrm{~cm}$, remaining below the third percentile. In addition, his penis remained relatively small and the length measured at the 10th percentile. Notably, his motor abilities had

Table 1. Clinical findings using Human Phenotype Ontology (HPO) term nomenclature (Köhler et al. 2019)

\begin{tabular}{ll}
\hline Cornelia de Lange clinical features (HPO terms) & Proband \\
\hline Microcephaly (HP:0000252) & Yes \\
Synophrys (HP:0000664) & Yes \\
Long eyelashes (HP:0000527) & Yes \\
Low-set ears (HP:0000369) & Yes \\
Anteverted nares (HP:0000463) & Yes \\
Long philtrum (HP:0000343) Smooth philtrum (HP:0000319) & Yes \\
Downturned corners of the mouth (HP:0002714) & Yes \\
High arched palate (HP:0000218) & No \\
Widely spaced teeth (HP:0000687) & No \\
Micrognathia (HP:0000347) & Yes \\
Short neck (HP:0000470) & No \\
Growth failure (HP:0001510) & Yes \\
Developmental delay (HP:0001263) & Yes \\
Autistic behavior (HP:0000729) & Yes \\
Abnormality of limbs (HP:0040064) & No \\
Hirsutism (HP:0001007) & Yes \\
Gastroesophageal reflux (HP:0002020) & No \\
Sensorineural hearing impairment (HP:0000407) & No \\
Ptosis (HP:0000508) & No \\
Cryptorchidism (HP:0000028) & No \\
External genital hypoplasia (HP:0003241) & Yes \\
Novel clinical features & \\
Hypercholesterolemia (HP:0003124) & Assumed unrelated \\
Hypertriglyceridemia (HP:0002155) & Assumed unrelated \\
\hline
\end{tabular}

${ }^{a}$ There have not been any reports of hypertriglyceridemia or hypercholesterolemia in SMCA1-caused CdLS so far. 
COLD SPRING HARBOR Molecular Case Studies
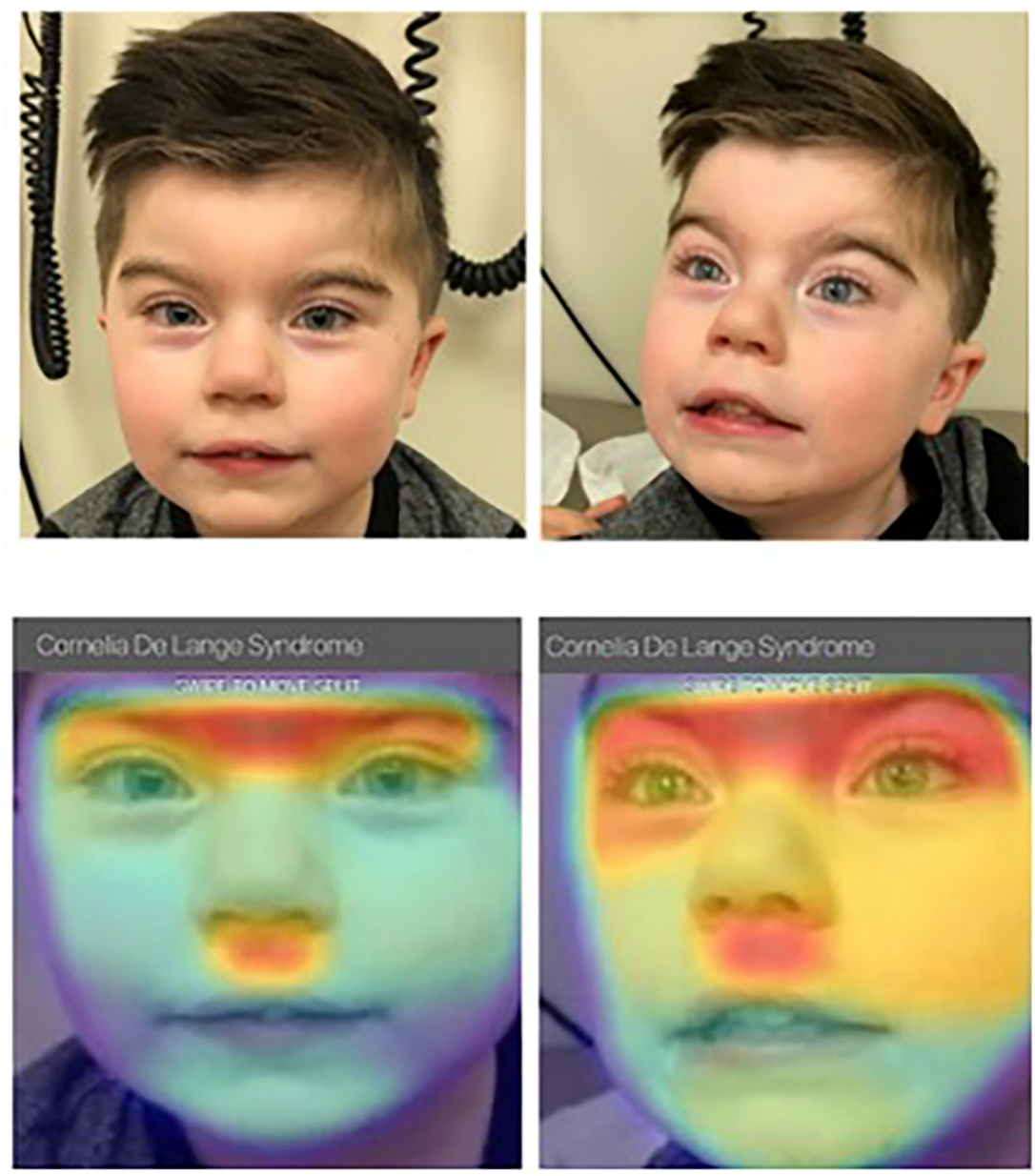

\section{LOW}

MED

\section{Gestalt}

Figure 1. Our patient's facial features and facial heatmap from Face2Gene facial recognition app show high correspondence with Cornelia de Lange gestalt. The distinctive facial features include synophrys, arched eyebrows, long eyelashes, low-set ears, long smooth philtrum, and downturned corners of mouth.

significantly improved, whereas his speech delay persisted, and he only had about 10 words at $5 \mathrm{yr}$ old and had received an autism spectrum disorder diagnosis. Recent assessment in the context of an individualized education plan, at age 6, reported aggression toward others, requiring constant supervision and maximum teacher cues to complete work at school. He is not toilet trained. He participates in a speech-impaired program and uses assisted technology devices, continuing to qualify for in-school speech and occupational therapy. Given his persistent delays, dysmorphic features, and the negative CdLS sequencing panel, a trio exome sequencing was ordered to look for an alternative diagnosis that mimics CdLS.

The exome identified two variants of uncertain significance, in trans, in a candidate gene, NSMCE2 (see Table 3). The NSMCE2 gene encodes a small ubiquitin-like modifier (SUMO) ligase, which plays a role in promoting homologous recombination and DNA damage repair (Potts and Yu 2005). Two patients have been reported by Payne et al. with NSMCE2 compound heterozygous frameshift mutations; both presented with primordial dwarfism, 
Table 2. Genomic findings Cornelia de Lange panel (buccal swab)

\begin{tabular}{|c|c|c|c|c|c|c|c|c|}
\hline Gene & Genomic location & HGVS cDNA & $\begin{array}{l}\text { HGVS } \\
\text { protein }\end{array}$ & Zygosity & Origin & $\begin{array}{c}\text { Variant } \\
\text { interpretation }\end{array}$ & $\begin{array}{l}\text { Level of } \\
\text { mosaicism }\end{array}$ & $\begin{array}{c}\text { ClinVar accession } \\
\text { number }\end{array}$ \\
\hline SMC1A & $\begin{array}{l}\text { Chr X:53,374,148 } \\
\text { (GRCh38) }\end{array}$ & $\begin{array}{c}\text { NM_006306.4 } \\
\text { c.793_796 } \\
\text { delGAG }\end{array}$ & p.Glu265del & Hemizygous & $\begin{array}{l}\text { De } \\
\text { novo }\end{array}$ & $\begin{array}{c}\text { Pathogenic } \\
\text { variant }\end{array}$ & $\begin{array}{l}60 \% \text { buccal swab } \\
4 \% \text { blood } \\
2 \% \text { blood }\end{array}$ & SCV001245515 \\
\hline
\end{tabular}

gonadal failure, and insulin-resistant diabetes, with fatty liver and hypertriglyceridemia. Our patient had some overlapping features with those presented by Payne et al. such as microcephaly and linear growth deficiency. Although liver function and insulin levels on our patient were normal, his fasting lipid profile indicated hypercholesterolemia (total cholesterol $275 \mathrm{mg} / \mathrm{dL}$, reference range $<170 \mathrm{mg} / \mathrm{dL}$ and LDL cholesterol $201 \mathrm{mg} / \mathrm{dL}$; reference range $<110 \mathrm{mg} / \mathrm{dL}$ ), as well as hypertriglyceridemia $(160 \mathrm{mg} / \mathrm{dL}$, reference range $<75$ $\mathrm{mg} / \mathrm{dL}$ ). But fasting lipid profiles from both parents were normal. We verified with the exome reporting laboratory that there were no reportable variants in known genes causing hyperlipidemia identifiable through exome sequencing. It is uncertain if variants on NSMCE2 contribute to his hyperlipidemia in any way. Despite some overlapping features, there were significant clinical differences between our patient and those described by Payne et al. as our patient has no signs of insulin resistance or lipodystrophy. Moreover, our patient's facial features were very divergent from those described by Payne et al. who displayed prominent midface, a small jaw, acanthosis nigricans, and skin tags.

At a follow-up clinic visit at $6 \mathrm{yr}$ old, considering the relatively high mosaicism rate of up to $30 \%$ reported (Krawczynska et al. 2019) in the clinically diagnosed mutation-negative CdLS patients, a CdLS gene panel (sequencing and CNV analysis), including ANKRD11, HDAC8, KMT2A, NIPBL, RAD21, SMC1A, and SMC3, on buccal swab specimens was ordered and identified a novel hemizygous variant, c.793_795delGAG, p.Glu265del, in SMC1A in 60\% of sequencing reads (33 of 56 reads), finally provided a definitive molecular diagnosis (Table 2 ).

\section{TECHNICAL ANALYSIS}

Cornelia de Lange NGS-based sequencing and a CNV analysis panel (HDAC8, NIPBL, RAD21, SMC1A, and SMC3) through EGL Genetics Laboratory (EGL) were performed in 2017 with blood as the specimen (please refer to Table 1 in Supplemental Materials for sequencing coverage information). In solution, hybridization of all coding exons within the genes tested was performed on genomic DNA: direct sequencing was done using next-generation short base pair read sequencing. Intronic variants $>3 \mathrm{nt}$ from the exon/intron boundary are not reported unless known to be pathogenic.

Trio exome sequencing through GeneDx laboratory was performed in 2018, with blood as the specimen from the proband and saliva as a specimen from both parents (please refer to Tables 2 and 3 in Supplemental Materials for sequencing coverage information). Genomic DNA from the specimen was enriched for coding regions and splice site junctions for most genes on the human genome, sequenced on an Illumina platform, and then filtered and analyzed using their custom analysis tool.

CdLS NGS-based sequencing and a CNV analysis panel (ANKRD11, HDAC8, KMT2A, NIPBL, RAD21, SMC1A, and SMC3) through GeneDx laboratory was performed in 2019 with a buccal swab specimen (please refer to Table 4 in Supplemental Materials for sequencing coverage information). The same methodology as trio exome sequencing is used, except sequencing was limited to the genes listed above. 
Table 3. Genomic findings exome sequencing trio (blood)

\begin{tabular}{|c|c|c|c|c|c|c|c|}
\hline Gene & $\begin{array}{l}\text { Genomic } \\
\text { location }\end{array}$ & HGVS cDNA & HGVS protein & Zygosity & $\begin{array}{l}\text { Parent of } \\
\text { origin }\end{array}$ & $\begin{array}{c}\text { Variant } \\
\text { interpretation }\end{array}$ & $\begin{array}{c}\text { ClinVar accession } \\
\text { number }\end{array}$ \\
\hline NSMCE2 & $\begin{array}{l}\text { Chr 8: } \\
\text { 8:125,091,778 } \\
\text { (GRCh38) } \\
\text { Exon 5 }\end{array}$ & $\begin{array}{c}\text { NM_173685.2 } \\
\text { c.346delT }\end{array}$ & p.Ser116LeufsX18 & Heterozygous & $\begin{array}{l}\text { Maternally } \\
\text { inherited }\end{array}$ & $\begin{array}{l}\text { Variant of } \\
\text { uncertain } \\
\text { significance }\end{array}$ & RCV000412505.1 \\
\hline NSMCE2 & $\begin{array}{l}\text { Chr 8: } \\
\text { 125,091,778 } \\
\text { (GRCh38) } \\
\text { Exon 6 }\end{array}$ & $\begin{array}{c}\text { NM_173685.2 } \\
\text { c. } 465 T>\text { T }\end{array}$ & p.Asp155Glu & Heterozygous & $\begin{array}{l}\text { Paternally } \\
\text { inherited }\end{array}$ & $\begin{array}{l}\text { Variant of } \\
\text { uncertain } \\
\text { significance }\end{array}$ & SCV001245059.1 \\
\hline
\end{tabular}

The variant on SMC1A was identified by the CdLS sequencing and CNV analysis. The panel was completed with the buccal swab sample in 2019. Upon discussion with GeneDx, which completed exome sequencing in 2018 , the variant was detected at $4 \%$ mosaicism in blood, which was below the laboratory's $20 \%$ threshold for reporting. EGL, which performed Cornelia de Lange panel sequencing in 2017, disclosed that the variant was present in $2 \%$ (4 out of 199) of reads in blood specimen. Again, it is below threshold for reporting.

Of note, in 2018, exome sequencing identified compound heterozygous variants of uncertain significance (VUS) on a candidate gene, NSMCE2 (Table 3).

Variants of the NSMCE2 gene have been described by Payne et al. (2014) in two female patients with primordial dwarfism, severe insulin resistance, microcephaly, small jaw, fatty liver, hypertriglyceridemia, and ovarian failure.

\section{VARIANT INTERPRETATION}

For the SMC1A variant, the criteria considered for classification were Cornelia de Lange-like phenotype, de novo variants not observed in large population cohorts (Lek et al. 2016), inframe deletion of one amino acid in a nonrepeat region, in silico analysis (including protein predictors and evolutionary conservation) supports a deleterious effect, and has not been previously published as pathogenic or benign.

\section{SUMMARY}

CdLS is a well-known genetic syndrome, recognizable by a distinctive appearance in patients with the classical phenotype, caused by heterozygous pathogenic variants on NIPBL in the majority of cases. In cases of milder phenotypes, facial characteristics can be less striking, limb anomalies are often absent, and cognitive impairment is less pronounced. Mild CdLS is more commonly caused by heterozygous pathogenic variants on SMC3, RAD21, and hemizygous pathogenic variants in HDAC8 or SMC1A. Somatic mosaicism has been frequently reported in the NIPBL gene. These NIPBL mosaic cases have generally correlated with a classic appearance and severe manifestations, suggesting that detected mosaicism does not necessarily ameliorate clinical features in this condition, especially for cases caused by variants in NIPBL (Castronovo et al. 2010; Gervasini et al. 2013). Somatic mosaicism has been reported less often in other genes that produce a milder CdLS phenotype.

To the best of our knowledge, our case is only the second reported CdLS-like patient with somatic mosaicism on SMC1A; this contrasts with high mosaicism on the NIPBL gene, which is well known. The scarcity of mosaic cases reported in the SMC1A gene could be attributed to its milder and less recognizable clinical features, or variable mosaicism levels in different 
tissues might be missed on certain types of specimens, as we saw in our patient. In addition, mosaicism levels can vary over time, even on the same tissue. Ansari et al. (2014) reported SMC1A mosaicism of $50 \%$ and $10 \%$, respectively, in two separate saliva samples of the same individual, producing an atypical phenotype with moderate growth retardation. Furthermore, germline mosaicism has been reported in several cases of the NIPBL gene but has also been suggested in a few SMC1A cases. They included a family with two affected daughters with a mild CdLS phenotype and parents with negative testing for the familial variant in blood, as well as a family with two affected daughters and a father with qualitative testing (chromatograph), indicative of low-level somatic mosaicism on SMC1A and no clinical features of the syndrome (Deardorff et al. 2007; Slavin et al. 2012). All of the above present a challenge for molecular testing strategies and genetic counseling in cases of CdLS-like patients but with an initially negative molecular result.

Here we report a case of somatic mosaicism on SMC1A that was detected at $60 \%$ in a buccal swab specimen, but detected at only $2 \%$ and $4 \%$ in two different blood specimens, by retrospectively reanalyzing raw data on previous testing because it is below the reporting threshold. This remarkable difference can be explained by the different origins of DNA in the specimens used. Buccal swabs contain a high proportion of epithelial cells, especially in children, in whom the mean proportion of buccal cells in buccal swabs was $90.3 \%$ in a recent study (Theda et al. 2018), whereas leukocytes are the cellular population used in blood samples.

In the current era of clinical genetics, the most cost-effective strategy for diagnosis of syndromes with poorly defined clinical features has become exome sequencing. This approach has the potential to identify new candidate genes in conditions with locus heterogeneity. Our case exemplifies a diagnostic odyssey and illustrates the challenge of somatic mosaicism in clinical practice, as low-level mosaicism can be disregarded by reporting laboratories if below a certain threshold. Our case illustrated that undetected mosaicism is a plausible explanation for unexpected negative molecular results, especially if a blood sample is the only specimen provided for testing. Selection against mutant cells, particularly in lymphocytes, has been suggested as one plausible mechanism and needs to be taken into consideration (Ansari et al. 2014). Fortunately, in CdLS, the computer-assisted facial analysis tool has a high sensitivity for CdLS. A diagnosis of CdLS was within the top five predicted syndromes for $97.9 \%$ of cases in a study by LaTorre-Pellicer, and sensitivity was high even for atypical cases and genes other than NIPBL (87.5\% for SMC1A) (LaTorre-Pellicer et al. 2020). Thus, a facial diagnostic tool can assist clinicians to a certain degree in deciding on the best test and specimen to send to increase diagnostic yield.

In conclusion, we suggest selecting different tissues for testing if CdLS is clinically suspected, even after negative results are obtained using a blood specimen, as mosaicism has been frequently reported in this condition.

\section{ADDITIONAL INFORMATION}

\section{Data Deposition and Access}

The SMC1A c.793_796delGAG and NSMCE2 c.465T > G variants were submitted to ClinVar (https://www.ncbi.nlm.nih.gov/clinvar/) and can be found under submission numbers SCV001245515 and SCV001245059.1.

\section{Ethics Statement}

ACMG patient consent for use of medical photography to be used in medical publications, including medical journals, textbooks, and electronic publications, was granted in writing by the parent of the patient. 
Competing Interest Statement The authors have declared no competing interest.

Received February 14, 2020; accepted in revised form April 14, 2020

\section{Acknowledgments}

We thank Cheryl Strauss for her critical review and editing for this manuscript, Erin Torti and the GeneDx ClinVar team for help with the submission of variants to the database, and Audrey Bibb, CGC, for her clinical care and coordination of genetic testing on this patient.

\section{Author Contributions}

H.L. conceptualized the case study, supervised the care of the patient, and critically reviewed and approved the final manuscript, as submitted; A.G.G. directly participated in the patient care, conducted a deep literature search, drafted the initial manuscript, and approved the final manuscript as submitted; and J.M. conducted the literature search and helped with clinical data collection and reviewed and approved the final manuscript, as submitted.

\section{REFERENCES}

Ansari M, Poke G, Ferry Q, Williamson K, Aldridge R, Meynert AM, Bengani H, Chan CY, Kayserili H, Avci S, et al. 2014. Genetic heterogeneity in Cornelia de Lange syndrome (CdLS) and CdLS-like phenotypes with observed and predicted levels of mosaicism. J Med Genet 51: 659-668. doi:10.1136/jmedgenet2014-102573

Castronovo P, Delahaye-Duriez A, Gervasini C, Azzollini J, Minier F, Russo S, Masciadri M, Selicorni A, Verloes A, Larizza L. 2010. Somatic mosaicism in Cornelia de Lange syndrome: a further contributor to the wide clinical expressivity? Clin Genet 78: 560-564. doi:10.1111/j.1399-0004.2010.01408

Deardorff MA, Kaur M, Yaeger D, Rampuria A, Korolev S, Pie J, Gil-Rodríguez C, Arnedo M, Loeys B, Kline AD, et al. 2007. Mutations in cohesin complex members SMC3 and SMC1A cause a mild variant of Cornelia de Lange syndrome with predominant mental retardation. Am J Hum Genet 80: 485-494. doi:10.1086/ 511888

de Graaf M, Kant SG, Wit JM, Willem Redeker EJ, Eduard Santen GW, Henriëtta Verkerk AJM, Uitterlinden AG, Losekoot M, Oostdijk W. 2017. Successful growth hormone therapy in Cornelia de Lange syndrome. J Clin Res Pediatr Endocrinol 9: 366-370 doi:10.4274/jcrpe.4349

Gervasini C, Parenti I, Picinelli C, Azzollini J, Masciadri M, Cereda A, Selicorni A, Russo S, Finelli P, Larizza L. 2013. Molecular characterization of a mosaic NIPBL deletion in a Cornelia de Lange patient with severe phenotype. Eur J Med Genet 56: 138-143. doi:10.1016/j.ejmg.2012.12.009

Köhler S, Carmody L, Vasilevsky N, Jacobsen JOB, Danis D, Gourdine JP, Gargano M, Harris NL, Matentzoglu N, McMurry JA, et al. 2019. Expansion of the Human Phenotype Ontology (HPO) knowledge base and resources. Nucleic Acids Res 47: D1018-D1027. doi:10.1093/nar/gky1105

Krawczynska N, Wierzba J, Wasag B. 2019. Genetic mosaicism in a group of patients with Cornelia de Lange syndrome. Front Pediatr 7: 203. doi:10.3389/fped.2019.00203

Latorre-Pellicer A, Ascaso Á, Trujillano L, Gil-Salvador M, Arnedo M, Lucia-Campos C, Antoñanzas-Pérez R, Marcos-Alcalde I, Parenti I, Bueno-Lozano G, et al. 2020. Evaluating Face2Gene as a tool to identify Cornelia de Lange syndrome by facial phenotypes. Int J Mol Sci 21: E1042. doi:10.3390/ijms21031042

Lek M, Karczewski KJ, Minikel EV, Samocha KE, Banks E, Fennell T, O'Donnell-Luria AH, Ware JS, Hill AJ, Cummings BB, et al. 2016. Analysis of protein-coding genetic variation in 60,706 humans. Nature 536: 285-291. doi:10.1038/nature19057

Payne F, Colnaghi R, Rocha N, Seth A, Harris J, Carpenter G, Bottomley WE, Wheeler E, Wong S, Saudek V, et al. 2014. Hypomorphism in human NSMCE2 linked to primordial dwarfism and insulin resistance. J Clin Invest 124: 4028-4038. doi:10.1172/JCI73264

Potts PR, Porteus MH, Yu H. 2006. Human SMC5/6 complex promotes sister chromatid homologous recombination by recruiting the SMC1/3 cohesin complex to double-strand breaks. EMBO J 25: 3377-3388. doi:10.1038/sj.emboj.7601218

Slavin TP, Lazebnik N, Clark DM, Vengoechea J, Cohen L, Kaur M, Konczal L, Crowe CA, Corteville JE, Nowaczyk MJ, et al. 2012. Germline mosaicism in Cornelia de Lange syndrome. Am J Med Genet A 158A: 1481-1485. doi:10.1002/ajmg.a.35381

Theda C, Hwang SH, Czajko A, Loke YJ, Leong P, Craig JM. 2018. Quantitation of the cellular content of saliva and buccal swab samples. Sci Rep 8: 6944. doi:10.1038/s41598-018-25311-0 


\section{COLD SPRING HARBOR Molecular Case Studies}

\section{A novel mosaic variant on SMC1A reported in buccal mucosa cells, albeit not in blood, of a patient with Cornelia de Lange-like presentation}

Aixa Gonzalez Garcia, Julia Malone and Hong Li

Cold Spring Harb Mol Case Stud 2020, 6: a005322

Access the most recent version at doi: $10.1101 / \mathrm{mcs} . a 005322$
Supplementary http://molecularcasestudies.cshlp.org/content/suppl/2020/06/12/mcs.a005322.D Material C1
References This article cites 13 articles, 2 of which can be accessed free at: http://molecularcasestudies.cshlp.org/content/6/3/a005322.full.html\#ref-list-1
License This article is distributed under the terms of the Creative Commons Attribution License, which permits unrestricted reuse and redistribution provided that the original author and source are credited.
Email Alerting Receive free email alerts when new articles cite this article - sign up in the box at the Service top right corner of the article or click here.

